\title{
THE BLACKSTAR: PERSONA, NARRATIVE, AND LATE STYLE IN THE MOURNING OF DAVID BOWIE ON REDDIT
}

\author{
Samiran CUlbert newcastle University
}

\begin{abstract}
This article considers how David Bowie's last persona, The Blackstar, framed his death through the narratives of mourning it provoked on the social media site Reddit. The official media narratives of death and the unofficial fan narratives of death can contradict each other, with fans usually bringing their own lived experiences to the mourning process. David Bowie is a performer of personas. While Bowie died in 2016, his personas have continued to live on, informing his legacy, his work, and his death reception. Through the concepts of persona, narrative, authenticity, late style, and mourning, this article finds that Bowie's Blackstar persona actively constructs fan's interaction with Bowie's death. Instead of separate and contradicting narratives, this article finds that users on Reddit underpin and extend the media narrative of his death, using Bowie's persona as a way to construct and establish their own mourning. As such, Bowie's last persona is further entrenched as one of authentic mourning, of a genius constructing his own passing. With these narratives, fans construct their own personas, informing how they too would like to die: artistically and with grace.
\end{abstract}

\section{KEY WORDS}

Persona; Mourning; David Bowie; Late Style; Narrative; Reddit

\section{INTRODUCTION}

The Blackstar persona presented by Bowie in his last album and singles helped structure his fans' mourning process. These last acts of artistry offered fans something to attach their mourning onto, allowing for them to work through their own mourning via Bowie's presentation of his own death. Korina Giaxoglou's defines mourning as "public and socially sanctioned displays of grief" (2014, p. 12), which are embedded in our cultural displays and practices. This article explores how these displays of mourning were considered through Bowie's Blackstar ${ }^{1}$ and how this was used by fans for their own mourning identity. This will be done by considering two threads on the social networking service (SNS) Reddit posted in the aftermath of Bowie's death. For this study, two different comment threads were chosen in two separate subreddits (themed Reddit boards) - r/music (2016) and r/indieheads (2016) - each focusing on the announcement of Bowie's death. By looking at these posts, this article will

\footnotetext{
${ }^{1}$ Here I am using Blackstar to mean the persona Bowie created. Throughout the text it will be written as Blackstar when it is the persona, 'Blackstar' for the song, and Blackstar for album.
} 
consider how the persona of the Blackstar is created in the users' initial expressions of loss and mourning. Firstly, this article will examine how Bowie has been considered as a persona throughout his career, focusing primarily on his post-1990s shedding of characters and the assumptions of authenticity which were embedded in this move. Secondly, Bowie's death will be discussed through the concepts of narrative and mourning. This will primarily be achieved by considering how the late style narrative has been attached to Bowie posthumously. Finally, this will be looked at through the lens of social interactions on Reddit, looking at how these posters used Bowie's Blackstar in their mourning.

The Blackstar album was released on January 8th just two days before Bowie's death (2016). In the aftermath of this release and Bowie's death, a posthumous persona was created with Blackstar at its centre. Throughout Bowie's life, a series of narratives allied to authenticity were constructed and maintained in our negotiations with him and his music. The concept of persona allows us to see how these are manifested and understood through both the presentation of the artist and how the fan constructs their own identities. In the narrative of Bowie's death, he is the empty vessel, where authenticities can be inscribed by different participants. It is in Bowie's death that the Blackstar persona encompasses and frames the narrative of his passing. It becomes the means through which we engage with Bowie's death and life in the present, bringing his past authenticities and personas into focus in the posthumous moment.

Mourning on social media has been discussed at length in recent scholarship, with focus primarily on the social worlds of Facebook, Twitter, and other sites (Gil-Egui, Kern-Stone \& Forman 2017; Gibson 2007; Jones 2004). The specific affordances of Reddit for mourning are addressed later in this article; for now, it is worth noting that digital technologies "challenge and reshape our existing understandings of the boundaries drawn between life and death" (Meese et al. 2015, p. 409). In turn, this has translated into work on celebrities and mourning with an emphasis on Facebook and Twitter (Garde-Hansen 2010; Klastrup 2018; Courbet \& FourquetCourbet 2014). Work has also already been completed on David Bowie and digital mourning through Twitter (Bulck \& Larsson 2017). However, each social media site represents a unique area of research, described as the "platform vernacular" (Gibbs et al. 2015, p. 255) of a social media site, encompassing the specific affordances and ways in which users can engage on these sites. This allows us to consider how the platform itself is structured for specific types of engagement: Instagram for photographs, Twitter for short form text, and so on. By focusing on Reddit, this article aims to find a different manifestation of mourning by the users on this site, examining how persona is an integral part of the online mourning process.

\section{Authenticating Bowie as A Persona}

David Bowie as an artist was and is constructed through his personas. When David Bowie died on $11^{\text {th }}$ January 2016 his physical body may have perished but his personas lived on. Musicians personas are narrative discourses consisting of multiple layers of image, text, and music (Barthes 1977), formed by various subjectivities and perspectives including fans, the press, and the artists themselves (Auslander 2006). Simon Frith states that a "star personality" (1996, p. 186 ) is built into the music we consume, informing all of our engagement with music objects, the musician, and fandom. This engagement happens on multiple levels, from the press (Black 2017), to fans (Cinque \& Remond 2016), and historical analysis of Bowie as a cultural object (Critchley 2016). In this way, Bowie exists as a balancing act of competing narratives, selves, and characters, providing a foundation for all of our engagement with him. 
The overarching narrative of Bowie's past is constructed around the changing personas he has performed (Bennett 2017; McLeod 2003; Perrot 2017; Reed, 2017). These changing personas allowed Bowie to "see the world and talk/sing about it through a different point of view" (Leorne 2015, p. 121), whilst seemingly expressing originality to his fans, the press, and other artists (Perrot 2017; Reed 2017; Stevenson 2015). The narrative of his changing selves is now ingrained into the histories and experiences connected to Bowie and our relationship to him on both a cultural and personal level. When we think of Bowie, we instantly think of Ziggy Stardust (1972), Aladdin Sane (1973), the Thin White Duke (1975), and the Goblin King (1986). These are a complex mix of myths, characters, and competing influences of the fans, the press, and the complex notion of Bowie the man. A musician's persona is just this: a concept tied up in a balancing act between competing narratives of commercialisation, audience, and artistic intentions (Auslander 2006) played out through artistic works, mediated objects, and performance. Simon Frith states that persona functions as a "site of narrative" (1996, p. 205), which underpins how we see and judge the musician's work and public self.

Rather than presenting a chronology of Bowie's life and career, we must consider that the narratives of Bowie's life are constructed through different personas. These different personas can be seen through the authenticities he is constructing and performing. In Allan Moore's deconstruction of authenticity in popular music (2002, p. 209), he outlines three ways in which authenticities are manifested in and around the popular music artist: first person, third person, and second person authenticity. The first-person authenticity is seen when a performer "succeeds in conveying the impression that his/her utterance is one of integrity, that it represents an attempt to communicate in an unmediated form" (Moore 2002, p. 214) to the audience. As such, it can be seen to be the persona of authenticity of the self, of seeing something 'real' and 'true' in the performer.

Third person authenticity "arises when a performer succeeds in conveying the impression of accurately representing the ideas of another, embedded within a tradition of performance" (Moore 2002, p.218). It is the authenticity we see embedded in folk traditions and the discourses which surround genres associated with national or cultural identities. Second person authenticity sees the artist giving "the impression to a listener that that listener's experience of life is being validated, that the music is telling it like it is for them" (Moore 2002, p. 220). The performer here is the conduit for the audience's thoughts, feelings, and authenticities. As such, it does not matter if the performer is not true to themselves, as they are representing truth to the audience. For the purpose of this article, focus will be placed on the first- and second-person authenticity. Philip Auslander states that a musician's persona is constructed by the tensions between "the press, the fan, and the artist themselves" (2006, pp. 115). Therefore, it stands to reason that the persona is also formed by the tensions between these authenticities, as they manifest themselves through different elements of the performer's career and life.

The narratives of Bowie's life can be seen to be underpinned by Moore's first and second person authenticities (Usher \& Fremaux 2015; Critchley 2016). We can see these authenticities manifested in two distinction periods of Bowie's life. The first was pre-1990s, where Bowie was still seen as a multitude of characters (Ziggy Stardust and so forth). This is established as second person authenticity, whereupon the character Bowie is playing is seen as fake (Critchley 2016), but is welcomed by the audience as a reflection of their own identities (Reed 2017; Perrot 2017). This second person authenticity was manifested through the Bowie which "inhabited his albums' lyrics but also developed mainly through the performance of his songs on tour and the related video performances" (Marshall 2017, p.570). Bowie was this "stage persona" (Marshall 2017, p. 570) which constructed and permeated the multimedia manifestation of Bowie. 
This began to change from the 1990s onwards, as Bowie strategically moved away from obvious displays of persona to embrace a first-person authenticity, a 'true' reflection of his self. He was followed up to this point in his career with the narrative of second person authenticity, one which existed on the premise that he was playing a persona but exhibiting some sort of true feeling or true reflection of what the audience needed to hear or see (Critchley 2016). Usher and Fremaux (2015) suggest the narrative of Bowie's work and persona of this period tipped towards a perceived authenticity of his true self. Through their analysis of press articles of this period, Usher and Fremaux highlight how the narratives being constructed around Bowie's personas were predicated on "a cathartic cleansing of performance of characters" (2015, p. 57). This cleanse allowed for the manifestation of a perceived authentic Bowie, free from pretence, where he "shed layers of artifice which his previous persona had required" (Usher \& Fremaux 2015 , p. 57). From the 1990 s onwards, this narrative was attached to a Bowie who was seen to be shedding his personas and uncovering the real man underneath. The concept of persona helps us understand how this is enacted. Celebrities offer their audiences the chance to create and maintain their own personas by mirroring them (Marshall 2017). As people engage with the narrative of Bowie's otherness, they see a chance to enact their own identities in the mirror of Bowie's (Critchley 2016; Leorne 2015; Perrot, 2017; Reed 2017).

First person authenticity can show us how Bowie and his music was considered not just in this period, but also the period up to his death. The 1990s shedding of personas reinforces the idea that, throughout his career, Bowie was showing a piece of his true self within all of his performances. This narrative allows the audience to engage with a perceived true Bowie, reinforcing their own identities in the process, as Bowie is seen to be reflective of a true self, an authentic identity underneath the façade. This can be understood by considering Erving Goffman's The Presentation of the Self in Everyday Life (1990). He states that "when an individual or performer plays the same part to the same audience on different occasions, a social relationship is likely to arise" $(1990$, p. 27) as the performance is developed over time by the interaction between performer and audience. In the 1990s Bowie renegotiated his approach to performance and identity, but this too was a musical persona, a performance of authenticity constructed through fans, Bowie, and the press (Usher and Fremaux 2015). This continued with the release of Bowie's final albums The Next Day and Blackstar.

Blackstar (2016) was released on January $8^{\text {th }}$, just two days before Bowie's death. Prior to this, The Next Day (2013) signalled Bowie's return from a long break from music, seeing Bowie in a perceived self-reflective mood (Stevenson 2015). The Next Day was seen as marking a further turn towards authenticity and self-reflection for Bowie, a first-person authenticity, but this was not mirrored in the reception for Blackstar. The cleanse seen in the post 1990s work was side-lined in the videos for the songs 'Lazarus' (2016) and 'Blackstar' (2015), which established complex imagery whilst simultaneously shifting and playing with genres. However, this album was seen as a continuation of Bowie's artistic endeavours and reinstated Bowie's persona as one which reflected the outsider, an artist who takes risks and who is not stuck in one genre or way of expression. He was seen to have separated from his previous work, as one Guardian review of the Blackstar album put it prior to his death: "It's a rich, deep and strange album that feels like Bowie moving restlessly forward, his eyes fixed ahead" (Petridis 2016). As such, the Blackstar period was not seen as a reflection of persona prior to his death, but as a reinstatement of Bowie as a consummate and ever forward-facing artist.

It can now seem obvious, with hindsight, where the Blackstar persona came from. However, on its release the visual elements of the singles, videos, and album were hard to decode. The word Blackstar was first heard being screamed by Bowie at the end of the title track, with Bowie claiming, "I'm a Blackstar" (Blackstar, 2016). We can see now that this was 
Bowie bringing a new persona to life, one which would frame his death. This was reinstated on the album cover, which was the first of Bowie's albums not to feature a picture of the artist himself but rather just one image, a black star. This, coupled with the videos for 'Lazarus' and 'Blackstar', reinforced the idea that Bowie developed a new persona substituting himself, the artist, for the iconography of the Blackstar, the image. There is speculation about the origins for this, with a lost Elvis record about death stalking a man being one of the most prominent, reinforced in the official documentary of this period The Last Five Years (2017). However, it is important to note that all of this is retrospective, informed and only now understood in the aftermath of Bowie's death. Prior to this, this persona is barely formed by Bowie's own standards; it only becomes clear in death, becoming a posthumous persona, reinforced by first person authenticity.

Although these two different authenticities represent different periods in Bowie's persona development, they both exist simultaneously in our cultural understanding of Bowie in the present. The concept of persona allows us to see how these are manifested and understood through both the presentation of the artist and how the fan constructs their own identities by mirroring them. All of our engagement with Bowie is through persona, whether through the lens of second- or first-person authenticity; there is always a character of Bowie to consume. In these narratives Bowie is the empty vessel where authenticities can be inscribed by different stakeholders. It is almost impossible to construct a full history of Bowie's personas as they adapt, change, and grow with each fan interaction and each new story told. Therefore, by considering Bowie through the two authenticities discussed, we can begin to see how some fan cultures understand and relate to the different narratives offered by Bowie's personas. However, death changes everything. The next section will consider how narratives are constructed posthumously and how this made Bowie the Blackstar.

\section{The BLACKSTAR, NARRATIVE, AND LATE STYLE}

Narratives are integral to our understanding of death. They "contextualise events in terms of narrative structures with which people are already familiar" (Bosticco \& Thompson 2005, p. 4). This is especially true in the post-death moment. By contextualising death in the act of narrative, mourners are ordering traumatic events into a familiar format. These narratives therefore allow for an "account that condenses a complicated set of events and perceptions into a single comprehensive unit" (Bosticco \& Thompson 2005, p. 10). Any ambiguity is ironed out through the establishing of a cohesive narrative as the media, the artist's representatives, and the fans look towards a central meaning in an artist's death. Anything which does not fit the narrative is filtered out with the "details adapted, ignored or changed so that the story being told has the desired effect" (Bosticco \& Thompson 2005, p. 9). The narratives of mourning are therefore an exercise in narrative limitation, which seek to find a dominant and satisfying narrative that adds continuity to the deceased's life.

The stories we construct and privilege in the aftermath of death shape our mourning and the legacy of the lost. When a celebrity dies, there is a scramble to piece together official media narratives and unofficial fan narratives of death. These two distinctions represent the different levels in which narratives of the dead are constructed posthumously. Official media narratives are established through press releases, statements and stories from family members, and the press, while unofficial fan narratives are constructed through conversations between fans, in person or on social media sites. Neither hold more or less sway in the realm of social media, and as we have seen in the discourses around Elvis Presley since his death, there is always a blurring of these two elements in the artist's legacy in our collective consciousness (Rodman 1996). These mourning narratives are constructed from multiple aspects of the 
deceased's life and their death event. These include cause of death, legacy, personal affect, and myths (Rodman 1996; Courbet \& Fourquet-Courbet 2014). This is all filtered through the narratives the person, or persona, has been associated with in life (van der Hoeven 2018; GardeHansen 2010). But through these narratives we make sense of the artist's death, the audience's own mourning, and the co-construction of the posthumous persona.

The narrative of Bowie's death was a continuation of the ideas being established in the decades prior, the first-person authenticity, the reflection backwards, and the turn towards a 'real' Bowie. Nick Stevenson, in his deconstruction of Bowie's The Next Day album, states that Bowie's later career began to "exhibit some of the features of late style" (Stevenson 2015, p.288). This has been further reinforced by Bowie's death, as a retrospective understanding of Bowie's career can trace a line from the first-person authenticity of the 1990s to his last two albums. Late style is attached to a period of an artist's life, near death usually, where "there is a marked shift in style and mode that is typically characterised as at the same time a form of 'life review'" (McMullan 2019, p. 61). The art produced "is not generically-bound; it is personal, essential, autobiographical; it is a supplement to the main body of the artist's work which is also a fulfilment of that work" (McMullan 2019, p. 61), coming to represent late style as an "authenticator of genius" (McMullan 2019, p. 62). In this way it mirrors the first-person authenticity discussed by Moore, as the artist pivots towards a more personally reflective creative output.

Gordon McMullan claims that we can understand the reaction and the narrative of Bowie's death through the concept of late style. The narrative both underscores Bowie as a genius and also reframes his late works as ones of intention, reinforcing the first-person authenticity and late style narrative that this work is "profoundly personal and redemptive" (McMullan 2019, p. 62). The Blackstar persona is seen in the shadow of late style as being "an authentic personal negotiation of age and death by a consummate artist" (McMullan 2019, p. 67). Thus, by viewing Bowie retrospectively through the lens of late style, we can see that the Blackstar persona propagated Bowie's death as authentic. As such, the Blackstar comes to symbolise the late style narrative constructed around Bowie and the reflecting of a first-person authenticity, namely the outward representation of the self. It reinforces Bowie's genius, reflection, and even redemption in the eyes of the fans, as Bowie did not just represent his own death but the mourning his fans will subsequently go through (Stevenson 2015).

The first-person authenticity reflection of Bowie in this narrative is seen almost exclusively through the persona of the Blackstar. The timing of the album release and Bowie's death offers narratives of mourning which construct a connection to late style. This has become the overriding story of Bowie's last years and is continually reinforced through discourses which surround his death in the press, as well as documentaries with his collaborators (Black 2017; The Last Five Years 2017). It is also important to note here that in the documentary about this period of Bowie's life, The Last Five Years, there were counteracting narratives from the director of the 'Blackstar' and 'Lazarus' music videos who didn't know Bowie was unwell and claim credit for visual representations of death and sickness in the music videos, particularly a hospital bed in the video for 'Lazarus' (2017). These visual clues have since been used as a way to reinstate Bowie as constructing and performing his own death. A glance at the comments underneath the YouTube videos of these songs reinforces this, with emphasis on how the visual elements heralded Bowie's forthcoming demise ('Blackstar' 2015; 'Lazarus' 2016). We see the continuity of both late style and mourning narratives at work in this, as the provenance of these ideas take a backseat in favour of the idea that Bowie constructed this world himself. 
The narratives surrounding Bowie positioned him as an authentic genius confronting death, continuing the legacy of Bowie's first-person authenticity from the 1990s onwards. Bowie's last albums and his Blackstar persona allowed fans and the press to side-line any narrative other than one which positioned Bowie as a self-reflective, authentic genius, who confronted his death with art. Thus, Bowie joins a long list of artists who have been seen to curate their own death through their work, and as such the press and the fans can make sense of Bowie's death. If the Blackstar persona underscores a first-person authenticity of death, then late style allows us to see how this was structured into the narrative of his death. But how did this persona affect the ways in which fans mourned his passing and, in turn, contribute further to his persona?

\section{REDDIT AND THE MOURNING OF BOWIE}

The concept of late style allows us to see how Bowie's persona was incorporated into the narrative of his death. Late style shows that Bowie was perceived to have positioned his death persona in relationship to an existing narrative trope, allowing fans to quickly frame their mourning. This narrative can be considered to be the official narrative of Bowie's death, produced by the press and Bowie's representatives and reinforced by first person authenticity. But the construction of a persona, as Auslander and Marshall have stated, is a product of not just official narratives but ones formed by peer-to-peer interactions, especially on social media sites. As such, it is important to consider fans' response to this persona and how their interactions in social media spaces underpin, construct, and inform how this persona is understood in the posthumous moment. This section will consider how the Blackstar persona was received posthumously on the SNS Reddit and how fans used this persona in their expressions of mourning. This will be achieved by considering a sample of posts which have been collected and anonymised from two Reddit threads, $\mathrm{r}$ /music and r/indieheads, on $11^{\text {th }}$ January 2016, breaking the news that David Bowie had died (r/music 2016; r/indieheads 2016). But first we must understand the Reddit platform itself and the unique affordances created by it.

Reddit offers an interesting space in which to study fan interactions in the post-death moment. Scholarship on Reddit has primarily centred on the darker side of the platform, focusing on events such as the Gamergate internet scandal and Reddit's role in the political events of 2016 (Maloney, Roberts, \& Graham 2019). These discourses have shaped the perception of Reddit in wider culture, where it is seen as a Wild West corner of the internet, ungoverned and a breeding ground for problematic views (Marantz 2018). The truth is murkier than this. The site boasts 100 million more active monthly users than Twitter (Clement 2020) and is in the top ten most visited sites in the world. With this in mind, it is a complex representation of everything that exists on the internet, from dedicated fan sites to activism, while also housing the darker elements present on all social media platforms. It is considered a relic from the forum-based social networks of the early web 2.0 era, set up as a collection of thematic pages, or subreddits, which are prefixed by the letter $r$, such as $r$ /politics.

Reddit is a "participatory culture platform" (Massanari 2013, p. 1), meaning it offers a space in which users both create and engage with content. The "platform vernacular" (Gibbs et al. 2015, p. 255), the site's specific construction and affordances, sees Reddit as a site situated around the "sharing of original and reposted content" (Massanari 2013, p. 2), where posts are made by members in boards or subreddits, known as threads. Users then earn 'karma' points, badges, and awards when their comments are upvoted; these awards "signal to the community that a particular comment or post is substantive and adds to the larger conversation" (Massanari 2013, p. 2). Conversely, when a comment is downvoted the poster's account loses karma points. As such, the 'game' of Reddit is to try and collect as many points as possible, as 
value resides in the poster's ability to engage with different threads in interesting ways. The gamification of Reddit (Massanari 2013) creates a space where valued comments are rewarded by the poster's peers. Posters receive instant validation on their interactions and can edit and adapt each post with corrections and updates when desired. If a post is continually downvoted it can disappear from the thread, be hidden, or even deleted by the admin. This platform vernacular privileges posts and narratives which uphold the themes of the subreddit, with posts that radically differ hidden from view. A culture of mutual dependency permeates these spaces as a result, as users are rewarded for upholding the overriding narratives established in the thread, subreddit, or community.

Reddit's construction offers a unique space to observe the interactions between fans in the immediate aftermath of a musician's death. The longer form comments, the allure of anonymity, and the archiving of posts after a short period of time, allows us to see how the news of Bowie's death was considered through his personas as the narratives were being formed. SNSs offer unique challenges to our ideas of narrative, especially in the fragmented nature of the platform's constructions. Story-making is embedded into the fabric of social media sites as users weave narratives around their own and others' lives. Stories in these spaces are "often ephemeral, small, located on the margins of other kinds of talk, and fall outside the canon of digital narrative" (Page 2012, p. 3). However, the longer form posts of Reddit show us how fuller narratives can be made on SNSs that privilege more developed interactions in specific themed spaces. Social media has also provided the space in which narratives of the deaths of musicians can be constructed, used, and reinforced by fans. "The collaborative nature of social media makes our usual ideas about single narrative and tellership redundant" (Page 2012, p. 13). As such, narratives of death on social media sites mirror that of persona construction in the musician, as fans, artists, and the media all construct and inform these narratives.

If we then turn to the two posts announcing Bowie's death on the subreddits $\mathrm{r} /$ music and $r$ /indieheads, we see how these narratives structure mourning in the space of the SNS. The comments on these subreddit threads cannot be easily placed into clear and distinctive categories. Rather, they blur between tenses, narratives, timeframes, and personas. Bulk and Larsson (2017) found that Bowie was primarily discussed in terms of his previous personas on Twitter. Although this is present on Reddit, the immediate period of posthumous narratives shows an overwhelming proportion of the posts concentrated on the Blackstar and how Bowie used this in his death.

\section{PAST AND PRESENT BOWIES}

One of the most prominent themes in these threads is the poster's uses of tense in regard to Bowie. Bowie exists in both the present and the past, with his personas acting as a means through which the posters engage with the man himself and his death. The posts ranged from short “RIP Starman," referencing Bowie's Ziggy Stardust, to more complex and evolving narratives (r/music 2016). For instance, one user posted: "It's apparent now his final album was $100 \%$ centred on his coming death and the duality of his human mortality and legendary stardom immortality" (r/music 2016). This poster concludes with "David's a Blackstar, a dead star... and Bowie is an immortal Lazarus" ( $\mathrm{r}$ /music 2016). Bowie is considered as both the artist who lives on and the physical body who is no more. We must now consider how this is underscored through the Blackstar.

The posters on these threads demonstrated an in-depth understanding of Bowie's construction and use of personas through his various characters and his authenticities. One user while positing their disbelief of Bowie's death, muses on this subject: "Bowie has put many of 
his selves to rest over the last half-century only to rise again with a different guise" ( $\mathrm{r}$ /music 2016). This post is then bookended with the statement that the Blackstar self must end with a "resurrection", an artistic statement that would be "hard to follow" (r/music 2016). We can see that there is a high level of persona literacy in this online space through posters' engagements with the multi-layered persona of Bowie. They are engaging with both first- and second-person authenticity, showcasing how Bowie's personas have changed over time. This becomes an integral part of the posters' approach to mourning Bowie. At the heart of this literacy is the idea that Bowie's death has been shaped and underscored by the Blackstar. As discussed previously, it was never a fully realised persona in Bowie's canon, however it provides the central understanding of Bowie's death in this space. The separation between the body and the persona highlights the understanding these mourners have of complex issues surrounding mourning and the celebrity. The narratives offered by the users both allows us to mourn the loss of the body but also establish the role of the persona as a separate and semi-autonomous entity. Here, Bowie is the empty vessel through which posters can ascribe their own ideas and authenticities while engaging with Bowie's past personas and his presentation of a first-person authenticity and late style.

\section{THE INTENTION NARRATIVE}

As discussed previously, the late style aesthetic and first-person authenticity that the Blackstar represents in this space is formed retrospectively through narratives. This retrospective narrativization is manifested through the posts on these threads as users seek the continuity that mourning narratives produce. This is underscored by one user stating that "only now do we realise that Blackstar was intended as his final incarnation: David Bowie as a dead man" ( $\mathrm{r} /$ music 2016). Throughout the posts on this thread there is an emphasis on retrospective realisations of what Bowie's last work meant to these mourners. They welcome the realisation that Bowie had used his last work to embrace death, acting as a cathartic release not just for himself, but for his fanbase. Attached to this retrospective understanding of Bowie's Blackstar as a narrative object is the idea of intention. The intention narrative manifests itself through the authenticity of Bowie's late style, a continuation of the first-person authenticity seen in his post90s era and his later works. This narrative of intent allows for the continuity and the meaning which is integral to the mourning process.

Bowie's intention is underscored by one user stating, "Lazarus sounds like he wrote his own eulogy now" (r/indieheads 2016). This is mirrored throughout a majority of the other posts on these threads. There is a retrospective understanding that the Blackstar was the means through which Bowie was communicating his impending death, his final authentic presentation. This characterisation allows mourners to engage with Bowie as a powerful persona. Rather than a sick man who died in a hospital, he is the consummate artist reinforcing a first-person authenticity of personal introspection. We can see this in posts which highlight his immortality and their disbelief, even refusal, to entertain the thought that Bowie was mortal. The late style narrative of reflection, introspection, genius, and authenticity is all present in these posts. This first-person authenticity is manifested in this appropriation of the Blackstar, where Bowie was seen to be presenting his own death, reflecting his own thoughts, feelings, and a posthumous persona to the audience.

Via Reddit's platform vernacular, the intention narrative dominates these two threads. This is reinforced through the mutual understanding that this is the only narrative of Bowie's death and anything else will not be heard. The personas inhabited by the posters follow this thread, with diverting voices punished with silence. A continuity of mourning is constructed in this act, as users increasingly enable one another to believe that the Blackstar was Bowie's way 
of telling them of his death. Believing that he constructed this himself allows users to think of his death, as one user points out as a "great way to bow out" (r/indieheads 2016). The narrative gives Bowie's death meaning for these users to pin their mourning onto. This is where the narratives of social media and the narratives of mourning intersect. In these threads the narrative of mourning wins out, with the cohesive story of Bowie's intention coming to dominate the posts. The structure of Reddit does not allow for what Moore, Barbour, and Lee term "the performance of the self", as age, gender, race is all hidden through the semianonymised structure (Moore, Barbour \& Lee 2017, p.4). However, these posts highlighting intention underline how interaction between personas on SNSs "can quickly become a pattern of action which then becomes routine, creating and then normalising a narrative of expected behaviour" (Moore, Barbour \& Lee 2017, p.4).

P. David Marshall states that celebrities offer the users on social media sites ways in which they themselves can approach their persona construction (2010). This may explain why the intent narrative was so enthusiastically undertaken by the users in this space. It reflected something within the mourners themselves, how they believe they would act given the circumstances, facing death with dignity and artistic flare, going out on their own terms. We can see this in the way in which one comment was downvoted to the point of being hidden in the thread in r/music (2016). In it a user stated how Bowie must have suffered greatly from cancer, insinuating that he must have died like their family member did, in a great deal of pain and indignity. As this did not continue the narrative being established in this space, this post was hidden from the thread. Users did not just want to believe this for Bowie's sake, but also their own. The persona of the users was under attack by the opposing narrative, therefore it had to be cut away from the thread, reinstating the intention narrative for all. When people mourn celebrities, it is rarely the celebrity themselves they are mourning; rather, it is an aspect of their own experiences and emotions.

\section{CONCLUSION}

Mourning is a time for reflection. It stands to reason that the death of a much-loved artist allows the audience to turn the introspection onto themselves. This is seen throughout posts on Reddit in micro narratives on illness, identity, and autobiography. Instead of multiple micronarratives which differed from the official media narrative surrounding Bowie's death (Stevenson 2015; McMullan 2019), this article found that the mourners in these threads maintained and reinstated Bowie as a curator of his own demise (Black 2017; Bulk \& Larsson 2017). They did this through the persona of the Blackstar which allowed them to meditate thoughtfully on Bowie's life, whilst reinstating the late style idea that Bowie's last act was one of intention (McMullan 2019), of first-person authentic reflection. The Blackstar is interwoven with this intention narrative. The analysis of Reddit shows how it becomes the means through which mourners can consider Bowie as a genius, as not a man coming to the end of his life, but rather an artist who foresaw and curated his own death in an authentic artistic act.

Mourning is an exercise in persona construction. The users on Reddit underscored the official media narratives of Bowie's passing while also adding further to the collective idea of Bowie through the intention narrative. Anything that did not underline the Blackstar as one of intention, artistry, and genius for curating his own death was buried in Reddit's platform vernacular. Instead of a pluralistic set of narratives you would expect to see on social media sites (Page 2012), there is a heavy consensus of narrative in this space, mutually understood, and collectively policed. The narrative comes into conflict with Reddit's own understanding of itself; instead of being a place that is open to discussions, in these mourning posts there is an emphasis on a collectively authorised narrative. In this approach Reddit does not differ from 
other SNSs, as differing opinions and differing narratives are rejected by the collective. This is a narrative of not just Bowie's persona, but the one of the fans who are mourning.

Thinking of Bowie as this persona, which is separated from the body, offers a release. The posters do not have to face the reality that Bowie is dead; they can however celebrate the fact that his personas still exist in the work he created, in a death he chose. There is a defence in this, as fans make sense of not just Bowie's death but their own. This is reflective of the ways in which Bowie made them feel when they first heard his music (Cinque \& Redmond 2016), through both second- and first-person authenticity. David Bowie represented a certain lifestyle to these mourners and in death he comes to represent a certain "deathstyle" (Christensen \& Gotved 2015, p. 5) in which they can see, and mourn, a part of themselves.

\section{WORKS CITED}

Auslander, P 2004, 'Performance analysis and popular music: A manifesto', Contemporary Theatre Review, vol. 14, no. 1, pp. 1-13.

Auslander, P 2006, 'Musical Personae', The Drama Review, vol. 50, no. 1, pp. 100-119.

Barthes, R 1977, Image, Music, Text, Harper Collins, London.

Bennett, A 2017, 'Wrapped in stardust: glam rock and the rise of David Bowie as pop entrepreneur', Continuum, vol. 31, no. 4, pp. 574-582.

Black, J 2017, 'The reification of celebrity: global newspaper coverage of the death of David Bowie', International Review of Sociology, vol. 27, no. 1, pp. 202-224.

Blackstar 2016 [CD-ROM], David Bowie, RCA.

Blackstar 2015, YouTube Video, David Bowie, 19th November, retrieved 19th June 2020, $<$ https://www.youtube.com/watch?v=kszLwBaC4Sw>

Bosticco, C \& Thompson, TL, 2005, 'Narratives and storytelling in coping with grief and bereavement', Omega: Journal of Death and Dying, vol. 51, no. 1, pp. 1-16.

Bulck, H Van Den \& Larsson, AO 2017, “There's a Starman waiting in the sky": Mourning David \#Bowie on Twitter', Convergence: The International Journal of Research into New Media Technologies, vol. 25, no. 2, pp. 307-323.

Christensen, DR \& Gotved, S 2015, 'Online memorial culture: An introduction', New Review of Hypermedia and Multimedia, vol. 21, no. 1-2, pp. 1-9.

Cinque, T \& Redmond, S 2016, 'Lazarus Rises: Storying the Self in the Migrant Fandom of David Bowie', IASPM@Journal, vol. 6, no. 1, pp. 7 - 24.

Clement, J 2020, Global Social Networks Ranked by Number of Users. Statista, retrieved: 10th June 2020, < https://www.statista.com/statistics/272014/global-social-networksranked-by-number-of-users/>

Courbet, D \& Fourquet-Courbet, MP 2014, 'When a celebrity dies...Social identity, uses of social media, and the mourning process among fans: the case of Michael Jackson', Celebrity Studies, vol. 5, no. 3, pp. 275-290.

Critchley, S 2016, On Bowie, Serpent's Tail, London.

David Bowie: The Last Five Years 2017, BBC, London. 7th January 2020.

Frith, S 1996 Performing Rites, Harvard University Press, Cambridge.

Garde-Hansen, J 2010, 'Measuring mourning with online media: Michael Jackson and real time memories', Celebrity Studies, vol. 1, no. 2, pp. 233-235.

Giaxoglou, K 2014, “'R.I.P. man ... u are missed and loved by many." Entextualising moments of mourning on a Facebook Rest in Peace group site', Thanatos, vol. 3, no. 1, pp. 10-28.

Gibbs, M, Meese, J, Arnold, M, Nansen, B \& Carter, M 2015, '\#Funeral and Instagram: death, social media, and platform vernacular', Information Communication and Society, vol. 18, no. 3, pp. 255-268. 
Gibson, M 2007, 'Death and mourning in technologically mediated culture', Health Sociology Review, vol. 16, no. 5, pp. 415-424.

Goffman, E 1990, The Presentation of the Self in Everyday Life, Penguin, London.

Jones, S 2004, '404 Not found: The internet and the afterlife', OMEGA: Journal of Death and Dying, vol. 49, no. 1, pp. 83-88.

Klastrup, L 2018, 'Death and Communal Mass-Mourning: Vin Diesel and the Remembrance of Paul Walker', Social Media and Society, vol. 4, no. 1, pp. 1 - 11.

Lazarus 2016, YouTube Video, David Bowie, $7^{\text {th }}$ January, retrieved: $19^{\text {th }}$ June 2020, $<$ https://www.youtube.com/watch?v=y-JqH1M4Ya8>

Leorne, A 2015, 'Dear Dr. Freud-David Bowie hits the couch: A psychoanalytic approach to some of his personae', in M Power, A Dillane and E Devereux (eds.), David Bowie: Critical Perspectives, New York, Routledge, pp. 111-127.

Maloney, M, Roberts, S \& Graham, T 2019, Gender, Masculinity and Video Gaming, Palgrave Pivot, London.

Marantz, A 2018, 'Reddit and the Struggle to Detoxify the Internet', New Yorker, retrieved 18th June 2020, <https://www.newyorker.com/magazine/2018/03/19/reddit-and-thestruggle-to-detoxify-the-internet>

Marshall, PD 2010, 'The promotion and presentation of the self: celebrity as marker of presentational media', Celebrity Studies, vol. 1, no. 1, pp. 35 - 48.

Marshall, PD 2017, 'Productive Consumption: Agency, Appropriation and Value in the Creative Consuming David Bowie.' Continuum, Vol. 31, no. 4, Pp. 564 - 573.

Marshall, PD \& Barbour, K 2015, 'Making Intellectual Room for Persona Studies: A New Consciousness and a Shifted Perspective', Persona Studies, vol. 1, no. 1, pp. 1-12.

Marshall, PD, Moore, C, \& Barbour, K 2015, 'Persona as method: exploring celebrity and the public self through persona studies', Celebrity Studies, vol. 6, no. 3, pp. 288-305.

Massanari, A 2013, 'Playful Participatory Culture: Learning from Reddit', Selected Papers of Internet Research, vol. 3, pp. 1-7.

McLeod, K 2003, 'Space Oddities: Aliens, futurism, and meaning in Popular Music', Popular Music, vol. 22, no.3, pp. 337 - 355.

McMullan, G 2019, 'Constructing a Late Style for David Bowie', in D Amigoni and G McMullan (eds.), Creativity in Later Life, New York, Routledge, pp 61 - 76.

Meese, J, Nansen, B, Kohn, T, Arnold, M \& Gibbs, M 2015, 'Posthumous personhood and the affordances of digital media', Mortality, vol. 20, no. 4, pp. 408-420.

Moore, A 2002, 'Authenticity as Authentication', Popular Music, vol. 21, no. 2, pp. 209 - 223.

Moore, C, Barbour, K \& Lee, K 2017, 'Five dimensions of online persona', Persona Studies, vol. 3, no. 1 , pp. $1-11$.

Page, R 2012, Stories and Social Media, Routledge, New York.

Perrott, L 2017, 'Bowie the Cultural Alchemist: Performing Gender, Synthesizing Gesture, and Liberating Identity', Continuum, vol. 31, no. 4, pp. 528-541.

Petridis, A 2016, 'David Bowie: Blackstar Review', The Guardian, retrieved 16th June 2020, https://www.theguardian.com/music/2016/jan/07/david-bowie-blackstar-review-aspellbinding-break-with-his-past

r/indieheads 2016, David Bowies Official Site: David Bowie Died Reddit, retrieved 20 th January 2020,

$<$ https://www.reddit.com/r/indieheads/comments/40fktn/david bowies official site david bowie died/>

r/music 2016, David Bowie Dies Age 69, Reddit, retrieved 20th January 2020. <https://www.reddit.com/r/Music/comments/40fkbu/david bowie dies age 69/>

Reed, K 2017, 'Singing the Alien: Velvet Goldmine and David Bowie's Glam Semiotics', Popular Music and Society, vol. 41, no. 5, pp. 556 - 571.

Rodman, G 1996, Elvis After Elvis, Routledge, London.

Stevenson, N 2015, 'David Bowie now and then: Questions of fandom and late style', in M Power, A Dillane and E Devereux (eds.), David Bowie: Critical Perspectives, New Haven, Routledge, pp. 280-294. 
Persona Studies 2020, vol. 6, no. 1

The Next Day 2013 [CD-ROM], David Bowie, Columbia.

Usher, B \& Fremaux, S 2015, 'Turn myself to face me: David Bowie in the 1990s and discovery of authentic self', in M Power, A Dillane, and E Devereux (eds.), David Bowie: Critical Perspectives, New York, Routledge, pp. 56-81. 